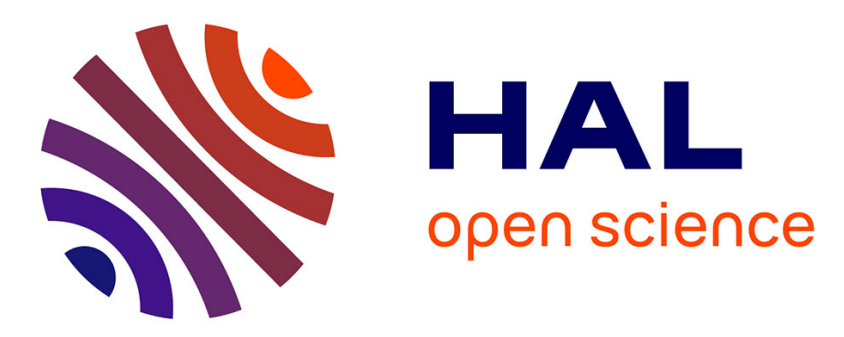

\title{
Thermoanalytical properties and structure of (As2Se3)100 - x(Sb2Se3)x glasses by Raman and 77Se MAS NMR using a multivariate curve resolution approach
}

Eva Černošková, J. Holubová, B. Bureau, Claire Roiland, Virginie Nazabal, R. Todorov, Z Černošek

\section{To cite this version:}

Eva Černošková, J. Holubová, B. Bureau, Claire Roiland, Virginie Nazabal, et al.. Thermoanalytical properties and structure of (As2Se3)100 - $\mathrm{x}(\mathrm{Sb} 2 \mathrm{Se} 3) \mathrm{x}$ glasses by Raman and 77Se MAS NMR using a multivariate curve resolution approach. Journal of Non-Crystalline Solids, 2016, 432 (B), pp.426-431. 10.1016/j.jnoncrysol.2015.10.044 . hal-01231157

\section{HAL Id: hal-01231157}

\section{https://hal-univ-rennes1.archives-ouvertes.fr/hal-01231157}

Submitted on 20 May 2016

HAL is a multi-disciplinary open access archive for the deposit and dissemination of scientific research documents, whether they are published or not. The documents may come from teaching and research institutions in France or abroad, or from public or private research centers.
L'archive ouverte pluridisciplinaire HAL, est destinée au dépôt et à la diffusion de documents scientifiques de niveau recherche, publiés ou non, émanant des établissements d'enseignement et de recherche français ou étrangers, des laboratoires publics ou privés. 


\section{Thermoanalytical properties and structure of $\left(\mathrm{As}_{2} \mathrm{Se}_{3}\right)_{100-\mathrm{x}}\left(\mathrm{Sb}_{2} \mathrm{Se}_{3}\right)_{\mathrm{x}}$ glasses by Raman}

and ${ }^{77}$ Se MAS NMR using a multivariate curve resolution approach

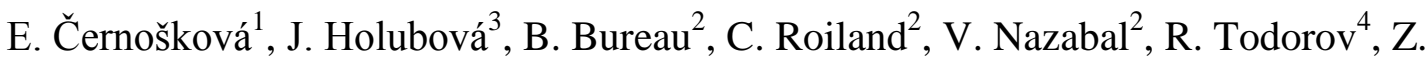
Černošek $^{3}$

${ }^{1}$ Joint Laboratory of Solid State Chemistry of IMC CAS, v.v.i., and University of Pardubice, Faculty of Chemical Technology, Studentská 84, 53210 Pardubice, Czech Republic, eva.cernoskova@upce.cz ${ }^{2}$ ISCR, UMR-CNRS 6226, University of Rennes 1, France.

${ }^{3}$ Department of General and Inorganic Chemistry, Faculty of Chemical Technology, University of Pardubice, Studentská 573, 53210 Pardubice, Czech Republic.

${ }^{4}$ Institute of Optical Materials and Technologies, Acad. G. Bonchev Str., bil. 109, 113 Sofia, Bulgaria.

Keywords: As-Sb-Se glass; DSC; StepScan DSC; Raman spectroscopy; ${ }^{77}$ Se MAS NMR; local structure

\section{Abstract}

The basic thermoanalytical characteristics and structure of $\left(\mathrm{As}_{2} \mathrm{Se}_{3}\right)_{100-\mathrm{x}}\left(\mathrm{Sb}_{2} \mathrm{Se}_{3}\right)_{\mathrm{x}}$ bulk glasses over the whole glass-forming region $(\mathrm{x}=0-50)$ were studied by DSC, StepScan DSC and both Raman and ${ }^{77}$ Se MAS NMR spectroscopies. The glass transition temperature, $\mathrm{T}_{\mathrm{g}}$, was found to increase only slightly from 184 to $190{ }^{\circ} \mathrm{C}$ with increasing $\mathrm{Sb}_{2} \mathrm{Se}_{3}$ content, and the changes in the isobaric heat capacity at $\mathrm{T}_{\mathrm{g}}$ are also nearly compositionally independent. However, the isobaric heat capacity of glasses decreases 
because of the higher atomic mass of antimony. The undercooled melts undergo crystallization when heated; $\mathrm{As}_{2} \mathrm{Se}_{3}$ crystallizes for $\mathrm{x} \leq 20$, and both stoichiometric triselenides crystallize for higher $\mathrm{x}$.

${ }^{77}$ Se MAS NMR spectroscopy was used for the first time in the structural study of this pseudobinary system. The results of both NMR and Raman spectroscopies were combined, and their chemometric analysis was used to elucidate the structure of the glasses over the whole glass-forming region. It was concluded that the structure is based on randomly distributed $\mathrm{AsSe}_{3 / 2}$ and $\mathrm{SbSe}_{3 / 2}$ trigonal pyramids bridged by common selenium atoms and corresponds to the transition structure between a "random covalent network model" (RCNM) and a "chains crossing model" (CCM).

\section{Introduction}

Chalcogenide glasses are a family of semiconducting materials that have been studied extensively, particularly for their application in infrared optics [1]. Ternary As-SbSe glasses were widely studied in the 1980s and 1990s and were recently "rediscovered" owing to their application for rewritable optical storage, e.g., [2,3]. Understanding the structure of these materials is currently in the spotlight.

The phase diagram of the $\mathrm{As}_{2} \mathrm{Se}_{3}-\mathrm{Sb}_{2} \mathrm{Se}_{3}$ pseudo-binary system, showing that this stoichiometric system exhibits simple eutectic behavior, was presented by Berkes and Myers in a study of phase relations and liquid structure in the system $\mathrm{As}^{-} \mathrm{Sb}_{2} \mathrm{Se}_{3}-\mathrm{Se}$ [4]. The authors do not state the exact eutectic composition, but based on the presented phase diagram, it can be estimated to be approx. 11 mol. $\% \mathrm{Sb}_{2} \mathrm{Se}_{3}$. The eutectic temperature was found to be $363 \pm 5{ }^{\circ} \mathrm{C}$, which is close to the melting temperature of $\mathrm{As}_{2} \mathrm{Se}_{3}, \mathrm{~T}_{\text {ons. }}=370{ }^{\circ} \mathrm{C}$. Platakis and Gatos studied the devitrification kinetics in an $\left(\mathrm{As}_{2} \mathrm{Se}_{3}\right)_{100-\mathrm{x}}\left(\mathrm{Sb}_{2} \mathrm{Se}_{3}\right)_{\mathrm{x}}$ system 
using either illumination by a $450 \mathrm{~W}$ xenon lamp or slow cooling of the melt. From melts with low $\mathrm{Sb}$ contents, the monoclinic $\mathrm{As}_{2} \mathrm{Se}_{3}$ phase was found to crystallize, whereas the orthorhombic $\mathrm{Sb}_{2} \mathrm{Se}_{3}$ phase crystallizes for Sb-rich melts [5]. Das et al. [6] investigated the thermodynamic and kinetic behavior of $\left(\mathrm{As}_{2} \mathrm{Se}_{3}\right)_{100-\mathrm{x}}\left(\mathrm{Sb}_{2} \mathrm{Se}_{3}\right)_{\mathrm{x}}$ alloys. They noticed that the glass transition temperature increases in the range 198 to $202{ }^{\circ} \mathrm{C}$ with increasing $\mathrm{Sb}_{2} \mathrm{Se}_{3}$ concentration, and the crystallization rate decreases. In addition to the glass transition, Sawan et al. [7] studied the electrical properties of As-Sb-Se glasses and found that $\mathrm{Sb}$ can be added to $\mathrm{As}_{2} \mathrm{Se}_{3}$ in amounts of up to approximately 19 at.\% to preserve the glassy state. Kato et al. reported the thermal properties and structure of As-Sb-Se and As-Sb-S glasses $[8,9]$ and the far-infrared reflectivity and Raman spectra of As-Sb-Se and As-Sb-S glasses [10]. They observed two dominant IR modes corresponding to $\left(\mathrm{AsSe}_{3 / 2}\right)$ and $\left(\mathrm{SbSe}_{3 / 2}\right)$ pyramidal units. The infrared intensity of the $\left(\mathrm{SbSe}_{3 / 2}\right)$ unit was found to be more than twice as strong as that of the $\left(\mathrm{AsSe}_{3 / 2}\right)$ unit. Mahadevan, Girindhar and Singh [11] intensively studied the calorimetric properties of As-Sb-Se glasses. In one of the most recent papers on As-Sb-Se glasses, Deli et al. [12] correlated the glass transition temperature with the optical gap and observed that the optical gap increases when $T_{g}$ rises. From structural analyses published in the literature [13-16], ${ }^{77}$ Se MAS NMR appears to be a very significant tool for the structural description of selenium-containing glasses, notwithstanding a low ${ }^{77}$ Se sensitivity resulting from its low natural abundance $(7.58 \%)$ and long longitudinal relaxation time (between 300 and $600 \mathrm{~s}$ [17-19]). The obtained results have confirmed the validity of the chain-crossing model for $\mathrm{As}_{\mathrm{x}} \mathrm{Se}_{1-\mathrm{x}}$ glasses for compositions rich in Se $(0<x<0.4)$. Freitas et al. [20] studied As-Se-S glasses using Raman spectroscopy. They reported the presence of mixed pyramidal AsSe ${ }_{3-\mathrm{x}} \mathrm{S}_{\mathrm{x}}$ units for all $\mathrm{x}$. The existence of these units precludes a phase separation in the studied glasses. G. Delaizir 
et al. [21], using wide-angle X-ray scattering and ${ }^{77}$ Se MAS NMR, observed that the progressive introduction of tellurium in $\mathrm{As}_{3} \mathrm{Se}_{(7-\mathrm{x})} \mathrm{Te}_{\mathrm{x}}$ glasses induces breakage of Se-Se bonds and formation of mixed pyramidal $\mathrm{AsSe}_{(3-\mathrm{x})} \mathrm{Te}_{\mathrm{x}}$ units. Using infrared reflectance spectroscopy, Kamitsos et al. [22] studied the structure of the same pseudo-binary stoichiometric system of the present study but based on sulfur. A glass structure formed by a random distribution of trigonal $\left(\mathrm{AsS}_{3 / 2}\right)$ and $\left(\mathrm{SbS}_{3 / 2}\right)$ pyramidal units bridged by sulfur atoms was proposed. Glotova and coworkers [23] studied nuclear quadrupole resonance $(\mathrm{NQR})$ and electron spin resonance (ESR) of $\left(\mathrm{As}_{2} \mathrm{Se}_{3}\right)_{0.78}\left(\mathrm{Sb}_{2} \mathrm{Se}_{3}\right)_{0.22}$, $\left(\mathrm{As}_{2} \mathrm{Se}_{3}\right)_{0.75}\left(\mathrm{Sb}_{2} \mathrm{Se}_{3}\right)_{0.25}$, and $\left(\mathrm{As}_{2} \mathrm{Se}_{3}\right)_{0.5}\left(\mathrm{Sb}_{2} \mathrm{Se}_{3}\right)_{0.5}$ glasses and identified two ${ }^{121} \mathrm{Sb}-\mathrm{NQR}$ lines and two ${ }^{75} \mathrm{As}-\mathrm{NQR}$ lines. Based on the analysis of the ESR results, they suggested the presence of hole-conductivity centers localized on chalcogen atoms and conduction electron centers localized on the arsenic atoms.

The aim of the present study is thermoanalytical and structural characterization by Raman and ${ }^{77} \mathrm{Se} \mathrm{NMR}$ of $\left(\mathrm{As}_{2} \mathrm{Se}_{3}\right)_{100-\mathrm{x}}\left(\mathrm{Sb}_{2} \mathrm{Se}_{3}\right)_{\mathrm{x}}$ stoichiometric glasses (or, in rewritten form, an $\mathrm{As}_{(40-2 \times / 5)} \mathrm{Sb}_{2 \times / 5} \mathrm{Se}_{60}$ system) for $\mathrm{x}$ covering a maximal possible glass-forming range. Differential scanning calorimetry (DSC) in conventional and StepScan DSC modes, XRD, Raman scattering and ${ }^{77} \mathrm{Se}$ MAS NMR are used. Because $\mathrm{Sb}_{2} \mathrm{Se}_{3}$ bulk glass cannot be prepared by melt quenching, the $\mathrm{Sb}_{2} \mathrm{Se}_{3}$ thin film must be used as the border compound, $\mathrm{x}=100$. In particular, chemometric analysis techniques will be used to interpret the Raman and ${ }^{77}$ Se MAS NMR data that are poorly resolved.

\section{Experimental}

\subsection{Sample preparations}


Bulk samples of $\left(\mathrm{As}_{2} \mathrm{Se}_{3}\right)_{100-\mathrm{x}}\left(\mathrm{Sb}_{2} \mathrm{Se}_{3}\right)_{\mathrm{x}}$ for $\mathrm{x}=0,5,10,20,30,40,50,60,70$ and 100 (polycrystalline $\mathrm{Sb}_{2} \mathrm{Se}_{3}$ for thin film deposition) were prepared by the melt quenching technique from $5 \mathrm{~N}$ purity elements. The quartz ampoules with appropriate amounts of elements with a total weight of $3 \mathrm{~g}$ were evacuated and sealed. Syntheses were performed in a rocking furnace at $850{ }^{\circ} \mathrm{C} / 24 \mathrm{~h}$. Ampoules with glass-forming melts were quenched in the cold water.

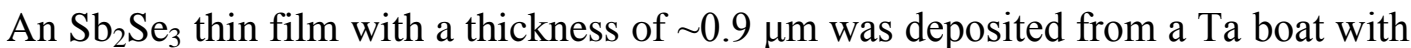
a preliminary calculated amount of polycrystalline $\mathrm{Sb}_{2} \mathrm{Se}_{3}$ sample. The layers were deposited by thermal evaporation at a deposition rate of $0.7-0.8 \mathrm{~nm} / \mathrm{s}$ on substrates from the microscopic glass.

\subsection{Experimental techniques}

XRD analysis of as-quenched glasses and the samples after DSC scans were performed using a D 8 Advance diffractometer (Bruker) using $\mathrm{CuK} \alpha$ radiation , $\lambda=$ $1.54178 \AA$, from $5.000^{\circ}$ to $65.000^{\circ}$ with a step of $0.020^{\circ}$ and a step time of $15.0 \mathrm{~s}$. Diffractograms were compared with the database PDF-4+; version 2014, Joint Committee on Powder Diffraction Standards, Int. Centre of Diffraction. Data, Swarthmore, PA, USA. The accuracy of the determination of the diffraction lines was $\pm 0.02^{\circ}$ of $2 \Theta$. To assign standards, accordance $\pm 0.05^{\circ}$ of $2 \Theta$ was used.

Energy-dispersive X-ray spectroscopy (EDX) employing a Jeol JSM 5500LV and a scanning electron microscope (accelerating voltage $20 \mathrm{kV}$ ) was used determine the chemical composition. The experimental error of analysis was \pm 1 at. $\%$.

A Diamond differential scanning calorimeter (DSC) (Perkin-Elmer) was used for the thermoanalytical study. Instruments were both temperature and enthalpy calibrated 
with the help of In and $\mathrm{Zn}$ standards; the correctness of the measurement of isobaric heat capacity was verified by measuring the monocrystalline corundum standard. Measurements were carried out under nitrogen purging. Samples (approximately $10 \mathrm{mg}$ ) were encapsulated in aluminum pans, and an empty pan was used as a reference. The accuracy of the temperature determination is better than $\pm 0.5^{\circ} \mathrm{C}$. The glass transition temperature, $\mathrm{T}_{\mathrm{g}}$, determined as a temperature at the $\Delta \mathrm{C}_{\mathrm{P}}$ midpoint, and the isobaric heat capacities, $\mathrm{C}_{\mathrm{p}}{ }^{\text {glass }}\left(\mathrm{T}_{\mathrm{g}}\right)$ and $\Delta \mathrm{C}_{\mathrm{P}}$, were measured with the help of the stepwise StepScan DSC technique. The temperature dependence of both the isobaric heat capacity and enthalpic changes of kinetic events were obtained. StepScan DSC measurements were carried out in the temperature range of 50 to $450{ }^{\circ} \mathrm{C}$ with a temperature step of $1{ }^{\circ} \mathrm{C}$, a heating rate of 10 ${ }^{\circ} \mathrm{C} / \mathrm{min}$, an isotherm duration $60 \mathrm{~s}$ and a maximal heat flow change allowed before next step of $\pm 0.005 \mathrm{~mW}$. For more details on this technique, see [24,25]. The crystallization of glass-forming melts was studied by heating in conventional DSC mode with a heating rate of $10^{\circ} \mathrm{C} / \mathrm{min}$.

Raman scattering measurements were carried out using an FTIR spectrometer IFS 55 with a Raman attachment FRA 106 (both Bruker) and a liquid nitrogen-cooled germanium detector. A Nd:YAG laser (1064 nm) was used for scattering excitation. Raman spectra were recorded at room temperature as an average of 250 scans with a resolution of $1 \mathrm{~cm}^{-1}$. Experimental spectra were reduced according the relation proposed by Shuker and Gammon [26].

The ${ }^{77}$ Se MAS NMR spectra were recorded at room temperature on an Avance 300 Bruker spectrometer operating at 57.28 MHz with a $4 \mathrm{~mm}$ MAS probe. The spectra were recorded with a spinning speed of $15 \mathrm{kHz}$, simultaneously averaging the chemical shift and reducing the homonuclear dipolar interaction between Se atoms. A Hahn spin echo 
sequence was applied to refocus the magnetization. Fourier transformation was performed on the entire magnetization to improve the signal-to-noise ratio and avoid any distortion of the baseline. The processing and acquisition parameters were as follows: $3.5 \mu$ s $\pi / 2$ pulse duration ( $7 \mu$ s for the $\pi$ pulse), $300 \mathrm{~s}$ recycle time, $1 \mathrm{MHz}$ spectral width, time domain $1 \mathrm{~K}$, 3000 accumulated scans. The external reference used for the chemical shift was a saturated solution of $\mathrm{Me}_{2} \mathrm{Se}$ in $\mathrm{CDCl}_{3}$ [27].

Chemometric analysis, specifically, multivariate curve resolution (MCR), included in the Solo+MIA chemometric software (Eigenvector Research Inc., USA) was used for analysis of the sets of Raman and ${ }^{77}$ Se MAS NMR spectra. The objective of MCR is to extract concentration profiles and pure component spectra. It is expected that data can be decomposed as nonnegative concentrations times nonnegative spectra, which is fulfilled in our case.

\section{Results and discussion}

\subsection{Thermoanalytical study}

EDX analysis confirmed, within the margins of the experimental error $\pm 1 \%$, the nominal compositions of all bulk samples and of the $\mathrm{Sb}_{2} \mathrm{Se}_{3}$ thin film. XRD did not find diffraction peaks for crystals either in the samples $\left(\mathrm{As}_{2} \mathrm{Se}_{3}\right)_{100-\mathrm{x}}\left(\mathrm{Sb}_{2} \mathrm{Se}_{3}\right)_{\mathrm{x}}$ for $\mathrm{x}=0-50$ or in the $\mathrm{Sb}_{2} \mathrm{Se}_{3}$ thin film. However, bulk samples for $\mathrm{x}>50$ were partially crystallized and thus were excluded from the study.

Although XRD analysis verified that the $\mathrm{Sb}_{2} \mathrm{Se}_{3}$ thin film is non-crystalline, neither conventional DSC nor StepScan DSC could find its glass transition [28]. This is not an isolated case for thin films; in fact, a glass transition was also not observed for, e.g., 
$\mathrm{Ge}_{2} \mathrm{Sb}_{2} \mathrm{Te}_{5}$ [29], $\mathrm{Ge}_{4} \mathrm{Sb}_{1} \mathrm{Te}_{5}, \mathrm{Ge}_{1} \mathrm{Sb}_{2} \mathrm{Te}_{4}, \mathrm{Ge}_{2} \mathrm{Sb}_{2} \mathrm{Te}_{5}$ and $\mathrm{Ag}_{0.055} \mathrm{In}_{0.065} \mathrm{Sb}_{0.59} \mathrm{Te}_{0.29}$ thin layers [30].

Concerning bulk glasses, compositional dependence of the glass transition temperature, $T_{g}$, the isobaric heat capacity of glass at $T_{g}, C_{p}{ }^{\text {glass }}\left(T_{g}\right)$, and the isobaric heat capacity difference at the glass transition, $\Delta \mathrm{C}_{\mathrm{P}}$, were obtained by StepScan DSC, and the results are summarized in Figs. 1 and 2. First, only one glass transition was found for each glass, proving that no segregation occurred, and thus, $T_{g}, C_{p}$ glass $\left(T_{g}\right)$ and $\Delta C_{P}$ can be correlated with nominal composition.

The glass transition temperature rises slightly but clearly from $184{ }^{\circ} \mathrm{C}$ for $\mathrm{x}=0$, i.e., $\mathrm{As}_{2} \mathrm{Se}_{3}$, to $189{ }^{\circ} \mathrm{C}$ for $\mathrm{x}=50$ as the $\mathrm{Sb}_{2} \mathrm{Se}_{3}$ content increases (Fig. 1). This behavior is similar to the results obtained by Das and coauthors [6], but the glass transition temperatures obtained in this study are lower by approximately $9{ }^{\circ} \mathrm{C}$. The chemical compositions of all glass samples agree with their nominal compositions; consequently, this difference relates to the StepScan DSC technique used for our measurements. This technique separates kinetic effects and thus shifts $\mathrm{T}_{\mathrm{g}}$ to a lower temperature for each composition [24]. The small increase in $\mathrm{T}_{\mathrm{g}}$ when $50 \%$ of the composition is changed can be explained by the fact that the bond energies of As-Se $(1.80 \mathrm{eV})$ and $\mathrm{Sb}-\mathrm{Se}(1.86 \mathrm{eV})$ are close to each other [31] and the geometry of the basic structural units are the sametrigonal pyramids. However, substitution of arsenic by antimony causes a decrease in the isobaric heat capacity at the glass transition temperature, $\mathrm{C}_{\mathrm{p}}{ }^{\text {glass }}\left(\mathrm{T}_{\mathrm{g}}\right)$, for $\mathrm{x}$ between 5 and 10 mol.\% of $\mathrm{Sb}_{2} \mathrm{Se}_{3}$ (Fig. 2). This can be understood considering the greater mass of antimony by a factor of 1.6 compared to that of arsenic and therefore the lower vibrational energy. However, compositional dependence of $\Delta \mathrm{C}_{\mathrm{P}}$ changes slightly over the whole glass-forming region, maximally by $0.016 \mathrm{~J} /$ (g.K) (Fig. 2). This finding agrees well with the facts that the 
only structural unit over the whole compositional range is a trigonal pyramid and that the bond energies of As-Se and Sb-Se are very similar. Thus, the changes in the vibrational amplitudes during the glass transition, i.e., the changes between glass and its undercooled melt at $\mathrm{T}_{\mathrm{g}}$, are only slightly compositionally dependent.

To obtain information on the undercooled melt stability, all bulk glasses were studied during heating by conventional DSC. First, one and then two broad crystallization peaks were observed depending on the content of $\mathrm{Sb}_{2} \mathrm{Se}_{3}$. The temperature of the second exothermic peak (this one at a lower temperature) decreases with increasing antimony content while the peak becomes sharper (Fig. 3). Thus, the temperature range of undercooled melt stability decreases, and consequently, the glass-forming ability by melt cooling decreases. XRD analyses indicate that for $\mathrm{x} \leq 20$, only $\mathrm{As}_{2} \mathrm{Se}_{3}$ crystallized, whereas when $\mathrm{x}>20$, both $\mathrm{As}_{2} \mathrm{Se}_{3}$ and $\mathrm{Sb}_{2} \mathrm{Se}_{3}$ undergo crystallization. These results agree with the eutectic phase diagram of the studied binary stoichiometric system [4]. For $\mathrm{x} \leq 10$, the crystallization of arsenic triselenide agrees with the phase diagram because the eutectic composition is close to $11 \mathrm{~mol} \% \mathrm{Sb}_{2} \mathrm{Se}_{3}$. However, for $\mathrm{x}>10$, the stoichiometric compound able to crystallize should be antimony triselenide; however, surprisingly, crystals of both stoichiometric selenides were found by XRD. This behavior can be understood by considering that the addition of $\mathrm{Sb}_{2} \mathrm{Se}_{3}$ to $\mathrm{As}_{2} \mathrm{Se}_{3}$ has a radical effect on the viscosity of the melt and the crystallization kinetics of $\mathrm{As}_{2} \mathrm{Se}_{3}$ crystals [4]. Pure $\mathrm{As}_{2} \mathrm{Se}_{3}$ is extremely viscous, and crystals grow very slowly, whereas at a composition of 20 mol.\% $\mathrm{Sb}_{2} \mathrm{Se}_{3}$, devitrification with the relatively rapid formation of $\mathrm{As}_{2} \mathrm{Se}_{3}$ crystals is relatively easy.

Regarding the endothermic peaks, their temperature decreases from the melting temperature of $\mathrm{As}_{2} \mathrm{Se}_{3}$ to the eutectic temperature for the samples with $\mathrm{x}$ lower than 20 ; for 
higher values, they remain independent of chemical composition (Fig. 3). Remarkably, a low area of the $\mathrm{As}_{2} \mathrm{Se}_{3}$ melting peak (low enthalpy change) is related to the extreme viscosity of the $\mathrm{As}_{2} \mathrm{Se}_{3}$ melt, as mentioned in the previous paragraph. A compositional peak shift observed for lower concentrations of $\mathrm{Sb}_{2} \mathrm{Se}_{3}(\mathrm{x}<20)$ corresponds to the shift of the dissolving peak of crystalline $\mathrm{As}_{2} \mathrm{Se}_{3}$ in the melt. However, the eutectic temperature is very close to the melting temperature of $\mathrm{As}_{2} \mathrm{Se}_{3}$; thus, the peaks of eutectic melting and the ensuing dissolution of $\mathrm{As}_{2} \mathrm{Se}_{3}$ merge into a single broader peak. This merging peak shifts to the eutectic temperature with increasing content of $\mathrm{Sb}_{2} \mathrm{Se}_{3}$. For samples with $\mathrm{x}=20$ and higher, i.e., samples with over-eutectic contents of $\mathrm{Sb}_{2} \mathrm{Se}_{3}$, only eutectic melting is observed in Figure 3 because the melting temperature of $\mathrm{Sb}_{2} \mathrm{Se}_{3}\left(590{ }^{\circ} \mathrm{C}\right)$ is out of the measurement range. Despite this, one can see a part of $\mathrm{Sb}_{2} \mathrm{Se}_{3}$ dissolving on the DSC traces for $\mathrm{x}=20$ and 30 .

\subsection{Structural study—Raman spectroscopy and ${ }^{77}$ Se MAS NMR}

The main feature of the set of Raman spectra is a broad band with the maximum more or less monotonically shifting from 233 to $191 \mathrm{~cm}^{-1}$ and a decreasing shoulder at approx. $239 \mathrm{~cm}^{-1}$ when the content of $\mathrm{Sb}_{2} \mathrm{Se}_{3}$ increases (Fig. 4). Based on the realistic supposition that the structural units of studied glasses are $\mathrm{AsSe}_{3 / 2}$ and $\mathrm{SbSe}_{3 / 2}$ trigonal pyramids only $[8,9,10]$, the compositional dependence of the Raman spectra simply reflects the fact that one structural unit replaces another isostructural one. Stemming from the fact that only one glass transition was observed for each type of glass, one must suppose selenium bridges (=As-Se-Sb=) to be an interconnection of arsenic- and antimonybased trigonal pyramids. Using multivariate curve resolution (MCR), chemometric analysis of the set of Raman spectra showed that the studied glasses can be well 
characterized by the linear combination of the three independent components (see Fig. 5). The variance captured by the MCR model is better than $99 \%$. Two of the resolved components on the inset of Fig. 5 correspond to the border compositions, $x=0$ (Comp. 1) and $\mathrm{x}=100$ (Comp. 2), and their vibrational modes reflect the fact that the 3D structure is composed only of $\mathrm{AsSe}_{3 / 2}$ and/or $\mathrm{SbSe}_{3 / 2}$ trigonal pyramids surrounded by the same structural units; from another perspective, this means that vibration modes correspond to vibrations of either $=\mathrm{As}-\mathrm{Se}-\mathrm{As}=$ or $=\mathrm{Sb}-\mathrm{Se}-\mathrm{Sb}=$ bridges. The third resolved component (Comp. 3) corresponds to the 3D structure of periodically alternating $\mathrm{AsSe}_{3 / 2}$ and $\mathrm{SbSe}_{3 / 2}$ pyramids; this corresponds to a composition of $\mathrm{x}=50$, and the vibrational modes are modes of $=\mathrm{As}-\mathrm{Se}-\mathrm{Sb}=$. A comparison of experimental and reconstructed spectra and residuals is shown in Fig. 6. We must stress that because the system under study is pseudobinary and stoichiometric, MCR analysis was also tested for only two components, but reconstruction of experimental spectra was practically impossible; the error reached almost $40 \%$.

To obtain the compositional dependence of three possible selenium bridges, ${ }^{77} \mathrm{Se}$ MAS NMR spectra were recorded for all $\left(\mathrm{As}_{2} \mathrm{Se}_{3}\right)_{100-\mathrm{x}}\left(\mathrm{Sb}_{2} \mathrm{Se}_{3}\right)_{\mathrm{x}}$ bulk glasses $(\mathrm{x}=0$ to 50) and for amorphous $\mathrm{Sb}_{2} \mathrm{Se}_{3}$ thin films (Fig. 7). Owing to the low abundance of ${ }^{77} \mathrm{Se}$ and its long longitudinal relaxation time, the signal-to-noise ratio is poor. The glassy network of $\mathrm{As}_{2} \mathrm{Se}_{3}(\mathrm{x}=0)$ composed of Se-connected $\mathrm{AsSe}_{3 / 2}$ pyramids gives rise to a single line centered around $390 \mathrm{ppm}$ relating to an As-Se-As unit [13-14]. The initial line of $\mathrm{As}_{2} \mathrm{Se}_{3}$ becomes increasingly asymmetric when the substitution of arsenic by antimony gradually increases. Thus, the broad spectrum encompasses a growing component at a lower chemical shift corresponding to the chemical shift of the ${ }^{77} \mathrm{Se}$ that is related to $\mathrm{Sb}-\mathrm{Se}-\mathrm{As}$ and maybe to $\mathrm{Sb}-\mathrm{Se}-\mathrm{Sb}$ for the richer composition in $\mathrm{Sb}$. Using MCR, the chemometric 
analysis of the set of ${ }^{77}$ Se MAS NMR spectra has also been performed, and three different selenium sites and the compositional dependencies of their scores were identified (Fig. 8). The detection of these three contributions is consistent with the twofold coordination state of selenium in chemistry. As in the case of Raman spectra, the model captures more than $99 \%$ of the variance of experimental data. Using the MCR results, the experimental spectra were reconstructed (see Fig. 9). Based on the chemical composition dependence of selenium site intensities, the first site characterized by a chemical shift of $393 \mathrm{ppm}$ is related to selenium in the $=\mathrm{As}-\mathrm{Se}-\mathrm{As}=$ structure, which is in full agreement with previous studies [14-17]. At the opposite side of the chemical shift scale, the line at $-19 \mathrm{ppm}$ is quite logically assigned to $=\mathrm{Sb}-\mathrm{Se}-\mathrm{Sb}=$ sequences. Thus, the third site, characterized by an intermediate chemical shift value of $206 \mathrm{ppm}$, is ascribed to the $=\mathrm{As}-\mathrm{Se}-\mathrm{Sb}=$ structural unit. The compositional trend of the fractions of these three sites obtained by MCR, Fig. 8, is basically the same as that obtained by the aforementioned analysis of Raman spectra (Fig. 5). The studied system can be shown as a solid solution formed by randomly distributed trigonal pyramids of $\mathrm{AsSe}_{3 / 2}$ and $\mathrm{SbSe}_{3 / 2}$ interconnected by mutual singleselenium bridges. This view agrees with the structure of $\left(\mathrm{As}_{2} \mathrm{~S}_{3}\right)_{100-\mathrm{x}}\left(\mathrm{Sb}_{2} \mathrm{~S}_{3}\right)_{\mathrm{x}}$ proposed on the basis of infrared reflectance spectroscopy, [22].

The fraction of structural units obtained by both Raman and NMR spectroscopy for each studied composition, Figs. 5 and 8, were averaged, and these mean values were compared with the two structural models, namely, a "chains crossing model" (CCM) and a "random covalent network model" (RCNM) (Fig. 10), for deeper elucidation of the structure of the studied glasses. The result shows that structure of glasses is "halfway" between these structural models. This is surprising because the current system is stoichiometric and pseudobinary and the As-Se and Sb-Se bond energies are similar; thus, no bonding partner 
of selenium should be preferred. Therefore, the structure of the glasses should be close to the ideal solution, and the RCN model should be suitable for its description. However, the deviation toward a $\mathrm{CCM}$ shows that $=\mathrm{As}-\mathrm{Se}-\mathrm{Sb}=$ bridges are somewhat more preferred. Entropy may have been responsible, but this has yet to be elucidated.

\section{Conclusions}

The basic thermoanalytical characteristics and structure of $\left(\mathrm{As}_{2} \mathrm{Se}_{3}\right)_{100-\mathrm{x}}\left(\mathrm{Sb}_{2} \mathrm{Se}_{3}\right)_{\mathrm{x}}$ bulk glasses covering the whole glass-forming region $(\mathrm{x}=0-50)$ and $\mathrm{Sb}_{2} \mathrm{Se}_{3}$ thin films $(\mathrm{x}=$ 100) used as the second border composition were studied by DSC, StepScan DSC and both Raman and ${ }^{77}$ Se MAS NMR spectroscopies.

The glass transition temperature was found to increase slightly from 184 to $190{ }^{\circ} \mathrm{C}$ when the content of $\mathrm{Sb}_{2} \mathrm{Se}_{3}$ increases from $\mathrm{x}=0$ to 50 . The glass transition of $\mathrm{Sb}_{2} \mathrm{Se}_{3}$ was not found. At the same time, when the glass transition increases, the isobaric heat capacity of glasses, which is measured at the glass transition onset on the glass side of the glass transition, decreases because arsenic atoms are replaced by antimony, which has a significantly higher atomic mass. Conversely, the compositional dependence of the change of isobaric heat capacity during glass transition is small, showing that structural changes between glasses and their undercooled melts are compositionally nearly independent. The undercooled melts are unstable and undergo crystallization when heated; for $\mathrm{x} \leq 20$, only arsenic triselenide crystallizes; for higher $\mathrm{x}$, both $\mathrm{As}_{2} \mathrm{Se}_{3}$ and $\mathrm{Sb}_{2} \mathrm{Se}_{3}$ crystalline phases were identified.

Raman spectroscopy, ${ }^{77}$ Se MAS NMR and especially chemometric analyses of compositional dependencies of both sets of spectra showed that the structure of the glasses over the whole glass-forming region is based on randomly distributed $\mathrm{AsSe}_{3 / 2}$ and $\mathrm{SbSe}_{3 / 2}$ 
trigonal pyramids bridged by common selenium atoms at the vertices of the pyramids. These findings indicate that the structure of glasses of a pseudobinary stoichiometric system substantially corresponds to the transition structure between models known as a "random covalent network model" (RCNM) and a "chains crossing model" (CCM). These conclusions are rather in agreement with previous works carried out in binary selenide systems, $\mathrm{As}_{\mathrm{x}} \mathrm{Se}_{1-\mathrm{x}}[14,16,17]$ and $\mathrm{Ge}_{\mathrm{x}} \mathrm{Se}_{1-\mathrm{x}}[15,18,19]$. Moreover, the present study shows that chemometric analysis is a very fruitful way to obtain some structural information from poorly resolved solid-state Raman and NMR spectra. To the best of our knowledge, this is the first time that such analyses have been carried out in that frame.

\section{Literature}

[1] A. Zakery, S.R. Elliot, Optical properties and applications of chalcogenide glasses. J. Non-Cryst. Solids 330 (2003) 1-13.

[2] V.I. Mikla, I.P. Mikhalko, V.V. Mikla, Laser-induced amorphous-to-crystalline phase transition in $\mathrm{Sb}_{x} \mathrm{Se}_{1-x}$ alloys, Mat. Sci. Eng. 83 (2001) 74-78.

[3] A. Kapoutsis, E.I. Kamitsos, I.P. Couleac, M.S. Iovu, Physics and Applications of NonCrystalline Semiconductors in Optoelectronic, Kluwer Academic Publisher, Netherland, A. Andriesh, M. Bertoletti editors, 1997.

[4] J.S. Berkes, M.B. Myers, Phase relations and liquid structure in the system $\mathrm{As}_{-}-\mathrm{Sb}_{2} \mathrm{Se}_{3}-$ Se, J. Electrochem. Soc. 118 (1971) 1485-1491.

[5] N.S. Platakis, H.C.Gatos, Devitrification characteristic of the semiconductor system (1x) $\mathrm{As}_{2} \mathrm{Se}_{3} \mathrm{xSb}_{2} \mathrm{Se}_{3}$, Solid State Sci. Tech. 119 (1972) 914-918.

[6] G.C. Das, N.S. Platakis, B. Bever, A thermodynamic and kinetic investigation of amorphous (1-x)As $\mathrm{Ae}_{3} \mathrm{xSb}_{2} \mathrm{Se}_{3}$ alloys, J. Non-Cryst. Solids 15 (1974) 30-44. 
[7] Y. Sawan, F.G. Wakim, M. El-Gabaly, M.K. El-Rayess, Study of the region of glass formation and electrical properties of the As-Se-Sb system, J. Non-Cryst Solids 41 (1980) $319-325$.

[8] M. Kato, S. Onari, T. Arai, Thermal properties and structure of As-Sb-Se and As-Sb-S glasses, Jpn. J. Appl. Phys. 20 (1981) 2013-2017.

[9] M. Kato, S. Onari, T. Arai, Study of structure of As-Sb-Se and As-Sb-S glasses, Jpn. J. Appl. Phys. 22 (1983) 1392-1399.

[10] S. Onari, M. Kato, T. Arai, Two fonon vibration spectra of amorpnous As-Sb-Se and As-Ab-S, J. Non-Cryst. Solids 95-96 (1987) 287-292.

[11] S. Mahadevan, A. Girindhar, A.K. Singh, Calorimetric measurements on As-Sb-Se glasses, J. Non-Cryst. Solids 11 (1986) 88-92.

[12] M.L. Deli, D.H. Boigny, G. Kra, The structural properties of $\mathrm{Sb}_{2} \mathrm{Se}_{3}-\mathrm{As}_{2} \mathrm{Se}_{3}$ and $\mathrm{Sb}_{2} \mathrm{STe}_{3}-\mathrm{As}_{2} \mathrm{Se}_{3}$ glasses, J. Non-Cryst. Solids 10 (2010) 59-65.

[13] B. Bureau, J. Troles, M. LeFloch, F. Smektala, G. Silly, J. Lucas, Solid state ${ }^{77}$ Se NMR investigation on arsenic-selenium glasses and crystals, Solid State Sci. 5 (2003) 219224.

[14] M. Deschamps, C. Roiland, B.Bureau, G.Yang, L. Le Poll, D. Massiot, ${ }^{77}$ Se solidstate NMR investigation on $\mathrm{As}_{\mathrm{x}} \mathrm{Se}_{1-\mathrm{x}}$ glasses using CPMG acquisition under MAS, Solid State Nuclear Mag. Res. 40 (2011) 72-77.

[15] C. Derric, D.C. Kaseman, I. Hung, Z.H. Gan, S. Sen, Observation of a continuous random network structure in $\mathrm{Ge}_{\mathrm{x}} \mathrm{Se}_{100-\mathrm{x}}$ Glasses: Results from high-resolution ${ }^{77} \mathrm{Se}$ MATPASS/CPMG NMR spectroscopy, J. Phys. Chem. B 117 (2013) 949-954. 
[16] D.C. Kaseman, I. Hung, Z.H. Gan, B. Aitken, S. Currie, S. Sen, Structural and topological control on physical properties of arsenic-selenide glasses, J. Phys. Chem. B 118 (2014) 2284-2293.

[17] K. Sykina, G.Yang, C. Roiland, L. Le Polles, E. Le Fur, C.J. Pickard, B. Bureau, E. Furet, ${ }^{77} \mathrm{Se}$ solid-state $\mathrm{NMR}$ of $\mathrm{As}_{2} \mathrm{Se}_{3}, \mathrm{As}_{4} \mathrm{Se}_{4}$ and $\mathrm{As}_{4} \mathrm{Se}_{3}$ crystals: a combined experimental and computational study, Phys. Chem. Chem. Phys. 15 (2013) 6284-6292.

[18] M. Deschamp, C. Genevois, S. Cui, C. Roiland, L. Lepollès, E. Furet, D. Massiot, B. Bureau, Structure of Arsenic Selenide Glasses Studied by NMR: Selenium Chain Length Distributions and the Flory Model, J. Phys. Chem. C 119 (2015) 11852-11857.

[19] K. Sykina, B. Bureau, L. Le Polles, C. Roiland, M. Deschamp, C.J. Pickard, E. Furet, A combined ${ }^{77} \mathrm{Se}$ NMR and molecular dynamics contribution to the structural understanding of the chalcogenide glasses, Phys. Chem. Chem. Phys. 16 (2014) 1797517982.

[20] J.A. Freitas, U. Strom, D.J. Treacy, Raman scattering of the mixed chalcogenide glass system $\mathrm{As}_{2} \mathrm{~S}_{\mathrm{x}} \mathrm{Se}_{3-\mathrm{x}}$, J. Non-Cryst Solids 59-60 (1983) 875-878.

[21] G. Delaizir, M. Dussauze, V. Nazabal, P. Lecante, M. Dollé, P. Rozier, E.L. Kamitsos, P. Jovari, B. Bureau, Structural characterizations of As-Se-Te glasses. J. Alloys Comp. 509 (2011) 831-836.

[22] E.I. Kamitsos, J.A. Kapoutsis, I.P. Culeac, M.S. Iovu, Structure and bonding in AsSb-S glasses by infrared reflectance spectroscopy, J. Phys. Chem. 101 (1997) 1061-11067. [23] O. Glotova, I. Korneva, N. Sinyavsky, B. Dobosz, R. Krzyminiewski, M. Jadzyn, M. Ostafin, B. Nogaj, Study of As-Sb-Se chalcogenide glasses by NQR and EPR spectroscopy methods, Central European J. Phys. 9 (2011) 387-391. 
[24] J. Holubová, Z. Černošek, E. Černošková, The study of the glass transition by the StepScan DSC technique, J. Optoelectron. Adv. Mater. 7 (2005) 2671-2676.

[25] Z. Černošek, J. Holubová, E. Černošková, Capability of conventional differential scanning calorimetry, temperature modulated DSC and StepScan DSC for the glass transition phenomenon study, Optoelectron. Adv. Mater. Rapid Commun. 1 (2007) 277280.

[26] R. Shuker, R.W. Gammon, Raman scattering selection-rule breaking and the density of states in amorphous materials, Phys. Rev. Lett. 25 (1970) 222-226.

[27] H. Duddeck. Selenium-77 Nuclear Magnetic Resonance Spectroscopy, Prog. Nucl. Magn. Reson. Spectrosc. 27 (1995) 1-23.

[28] E. Černošková, R. Todorov, Z. Černošek, J. Holubová, L. Beneš, Thermal properties and the structure of amorphous $\mathrm{Sb}_{2} \mathrm{Se}_{3}$ thin film, J. Therm. Anal. Calorim. 118 (2014) 105110.

[29] J. Orava, A.L. Greer, B. Gholipour, D.W. Hewak, C.E. Smith, Characterization of supercooled liquid $\mathrm{Ge}_{2} \mathrm{Sb}_{2} \mathrm{Te}_{5}$ and its crystallization by ultrafast-heating calorimetry, Nature Mater. 11 (2012) 279-283.

[30] J.A. Kalb, M. Wuttig, F. Spaepen, Calorimetric measurement of structural relaxation and glass transition temperatures in sputtered films of amorphous Te alloys used for phase change recording, J. Mater. Res. 22 (2007) 748-754.

[31] L. Tichý, H. Tichá, Covalent bond approach to the glass transition temperature of chalcogenide glasses, J. Non-Cryst. Solids 189 (1995) 141-146. 


\section{Figure captions}

Fig. 1 Compositional dependence of the glass transition temperature.

Fig. 2 Compositional dependence of the isobaric heat capacity of glass at the beginning of the glass transition region and difference of the isobaric heat capacity during glass transition.

Fig. 3 DSC traces of bulk glasses. For details, see the text.

Fig. 4 Reduced Raman spectra of $\left(\mathrm{As}_{2} \mathrm{Se}_{3}\right)_{100-\mathrm{x}}\left(\mathrm{Sb}_{2} \mathrm{Se}_{3}\right)_{\mathrm{x}}$ glasses $(0 \leq \mathrm{x} \leq 50)$ and thin films $(\mathrm{x}$ $=100)$.

Fig. 5 Compositional dependence of the scores on components for reconstruction of experimental Raman spectra by means of their linear combination obtained by MCR analysis of set of experimental spectra of $\left(\mathrm{As}_{2} \mathrm{Se}_{3}\right)_{100-\mathrm{x}}\left(\mathrm{Sb}_{2} \mathrm{Se}_{3}\right)_{\mathrm{x}}$ glasses $(0 \leq \mathrm{x} \leq 50)$ and film $(\mathrm{x}=100)$. Inset: Components resolved by MCR analysis.

Fig. 6 Experimental (black) and reconstructed (red) Raman spectra and residuals (blue) obtained using the MCR model.

Fig. $7{ }^{77} \mathrm{Se} \mathrm{MAS} \mathrm{NMR} \mathrm{spectra} \mathrm{of}\left(\mathrm{As}_{2} \mathrm{Se}_{3}\right)_{100-\mathrm{x}}\left(\mathrm{Sb}_{2} \mathrm{Se}_{3}\right)_{\mathrm{x}}$ glasses $(0 \leq \mathrm{x} \leq 50)$ and thin film $(\mathrm{x}$ $=100)$.

Fig. 8 Compositional dependence of the scores on components for reconstruction of experimental ${ }^{77}$ Se MAS NMR spectra by means of their linear combination obtained by MCR analysis of a set of experimental spectra of $\left(\mathrm{As}_{2} \mathrm{Se}_{3}\right)_{100-\mathrm{x}}\left(\mathrm{Sb}_{2} \mathrm{Se}_{3}\right)_{\mathrm{x}}$ glasses $(0 \leq \mathrm{x} \leq 50)$ and film $(\mathrm{x}=100)$. Inset: Components resolved by MCR analysis.

Fig. 9 Experimental (black) and reconstructed (red) ${ }^{77}$ Se MAS NMR spectra and residuals (blue) obtained using the MCR model.

Fig. 10 Comparison of the MCR results with RCNM and CCM structural models. For details, see the text. 


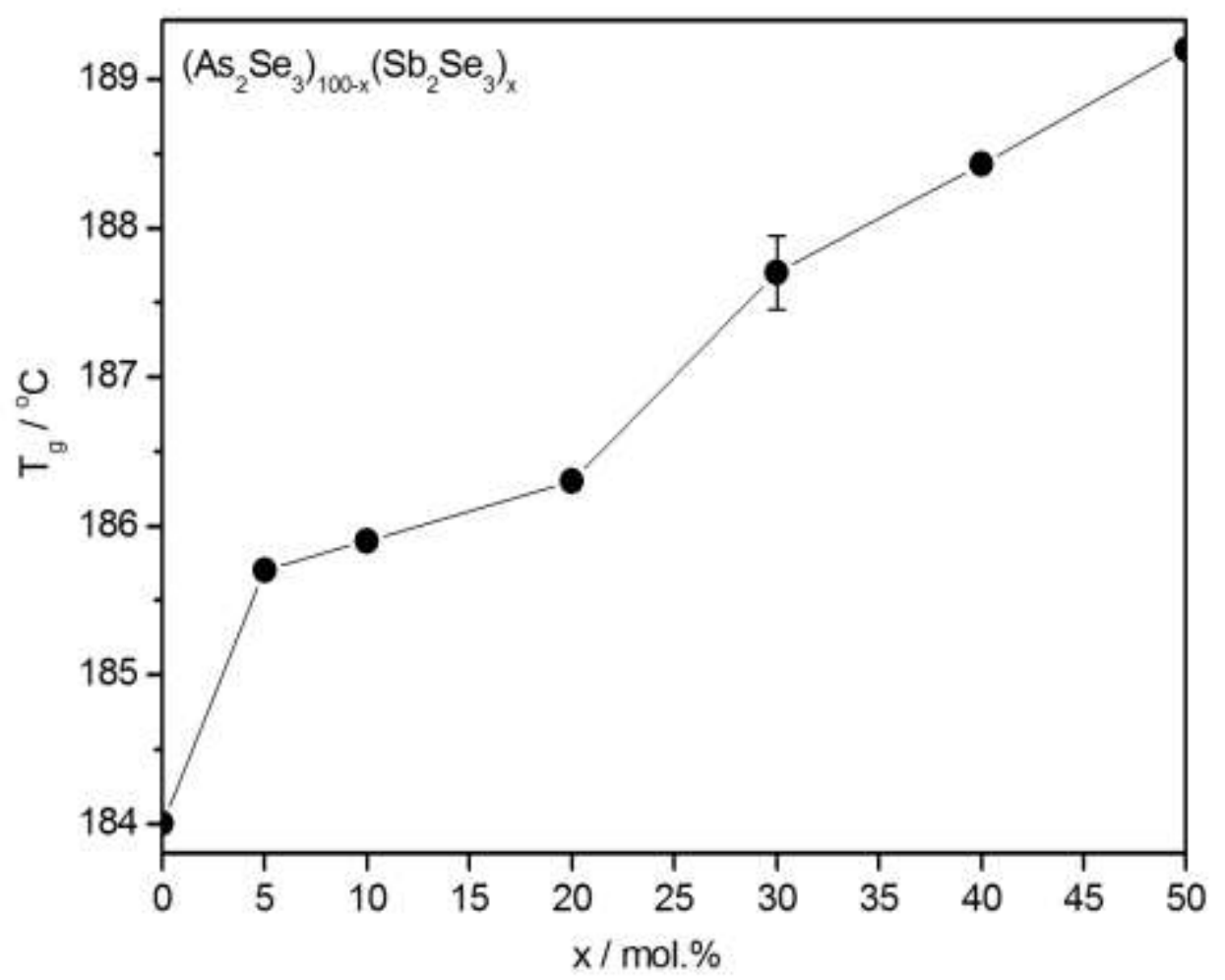

Fig. 1 


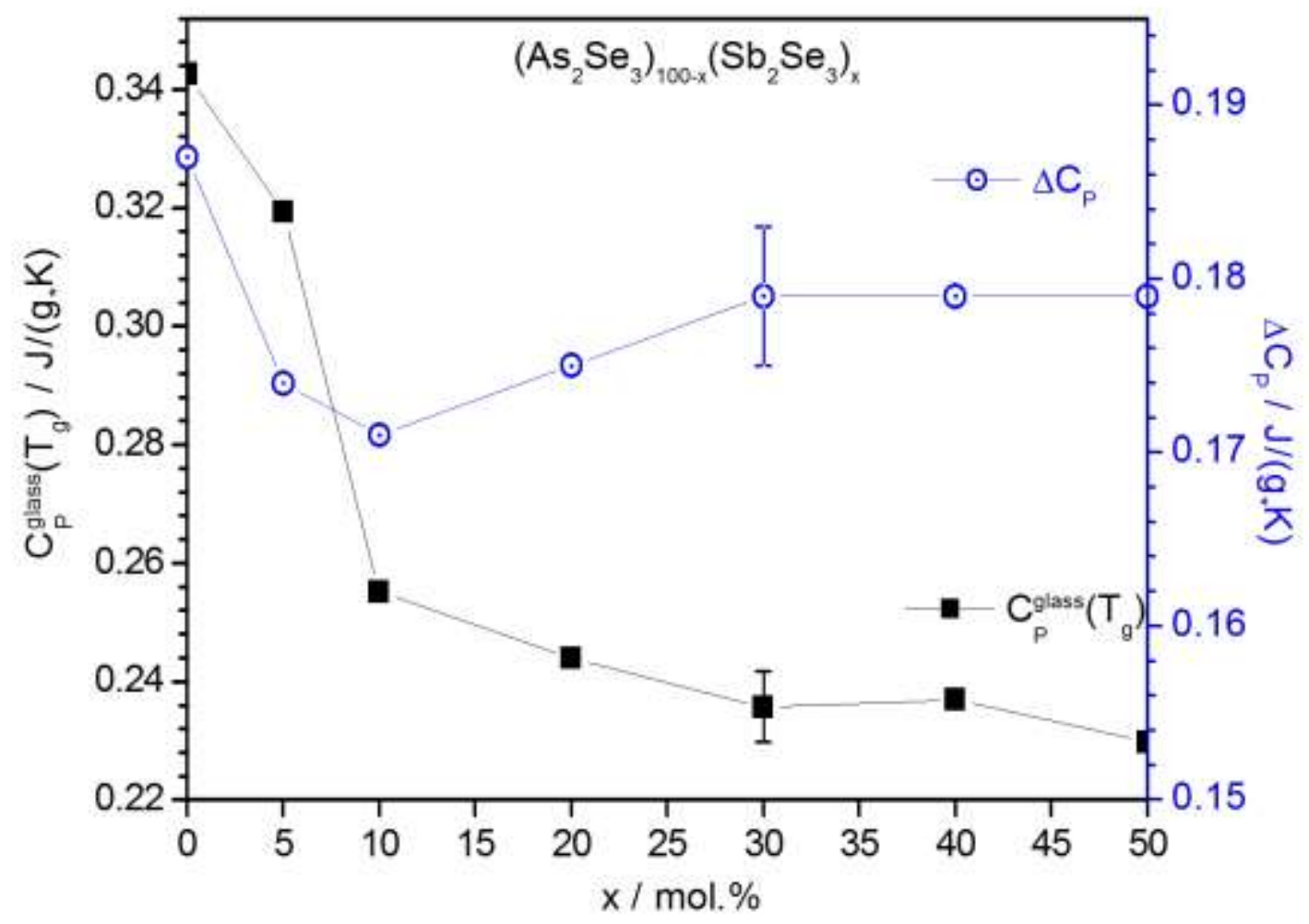

Fig. 2 


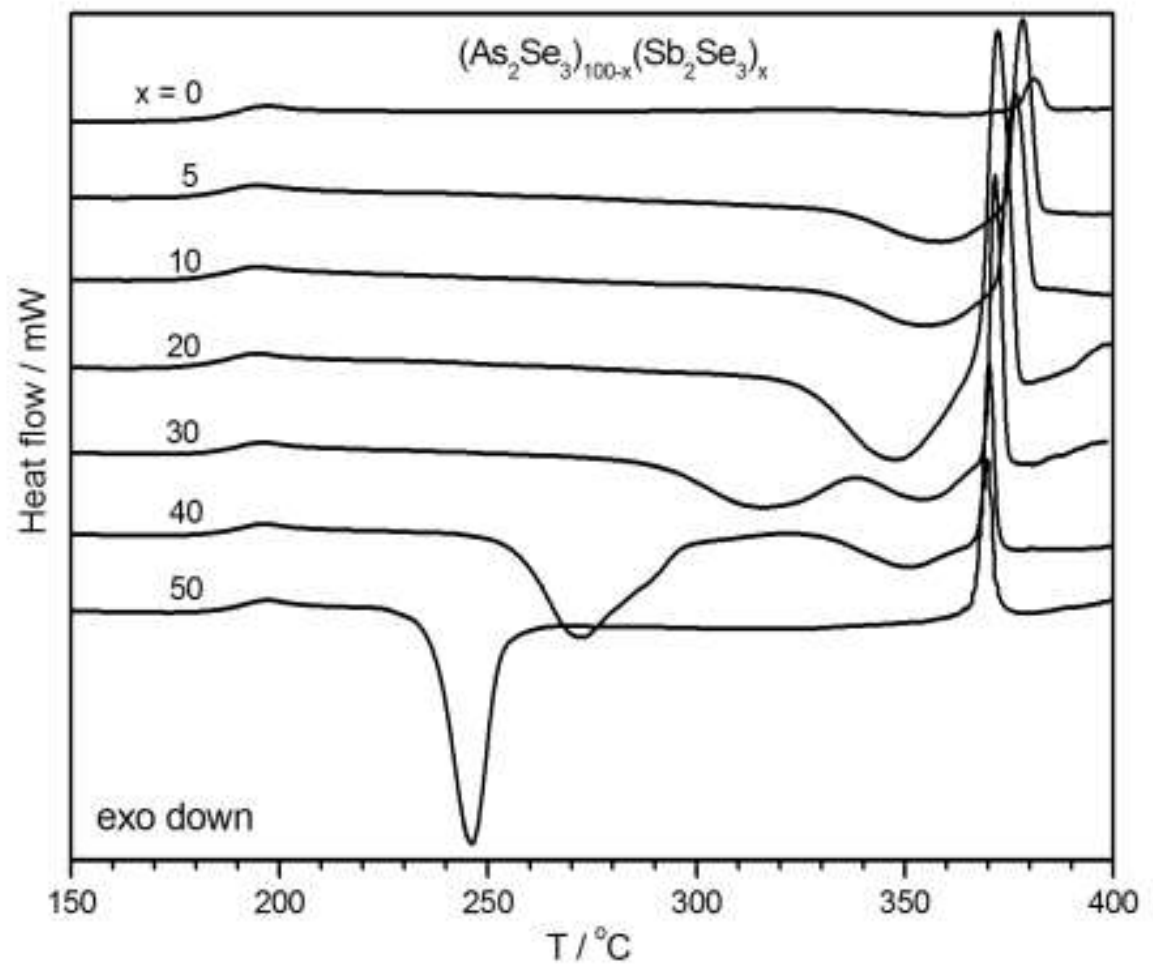

Fig. 3 


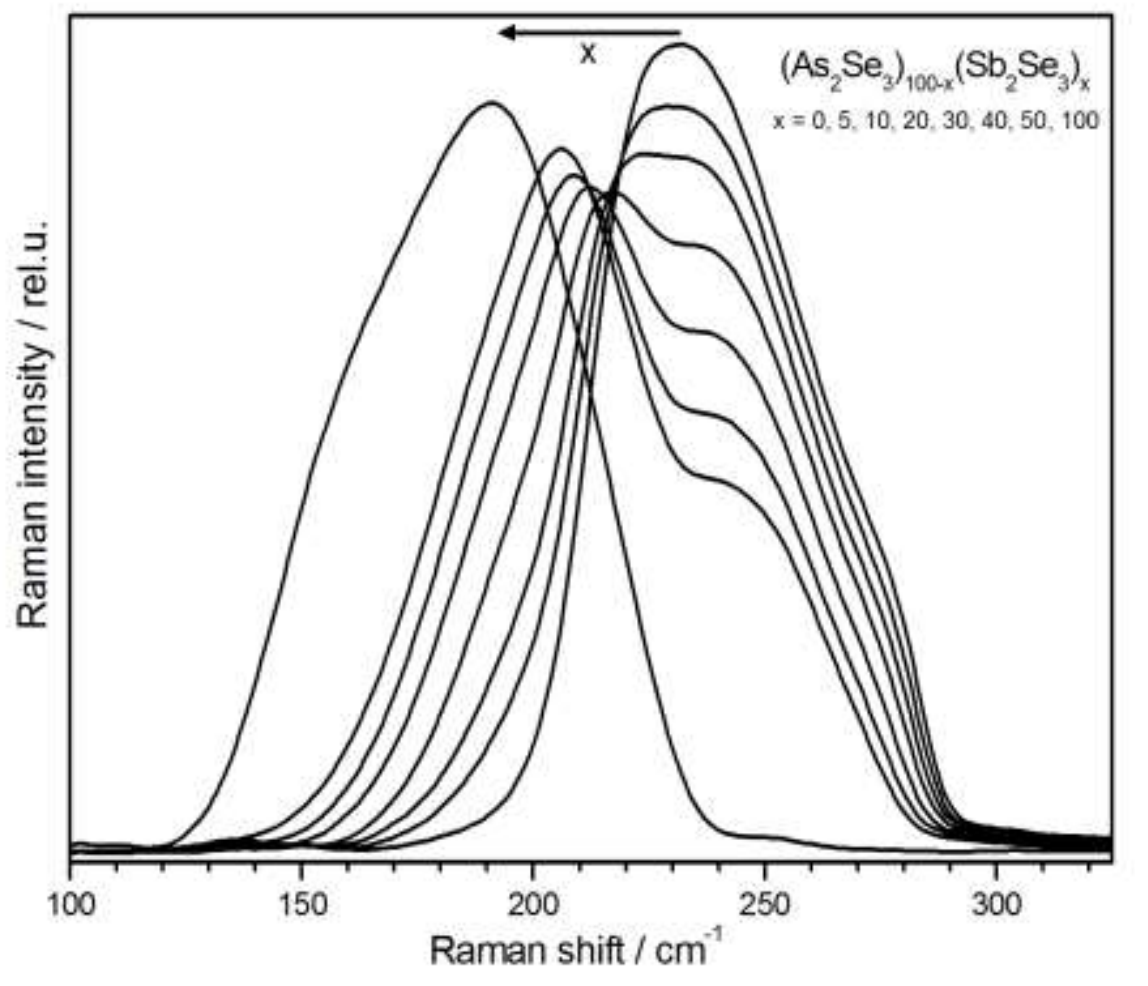

Fig. 4 


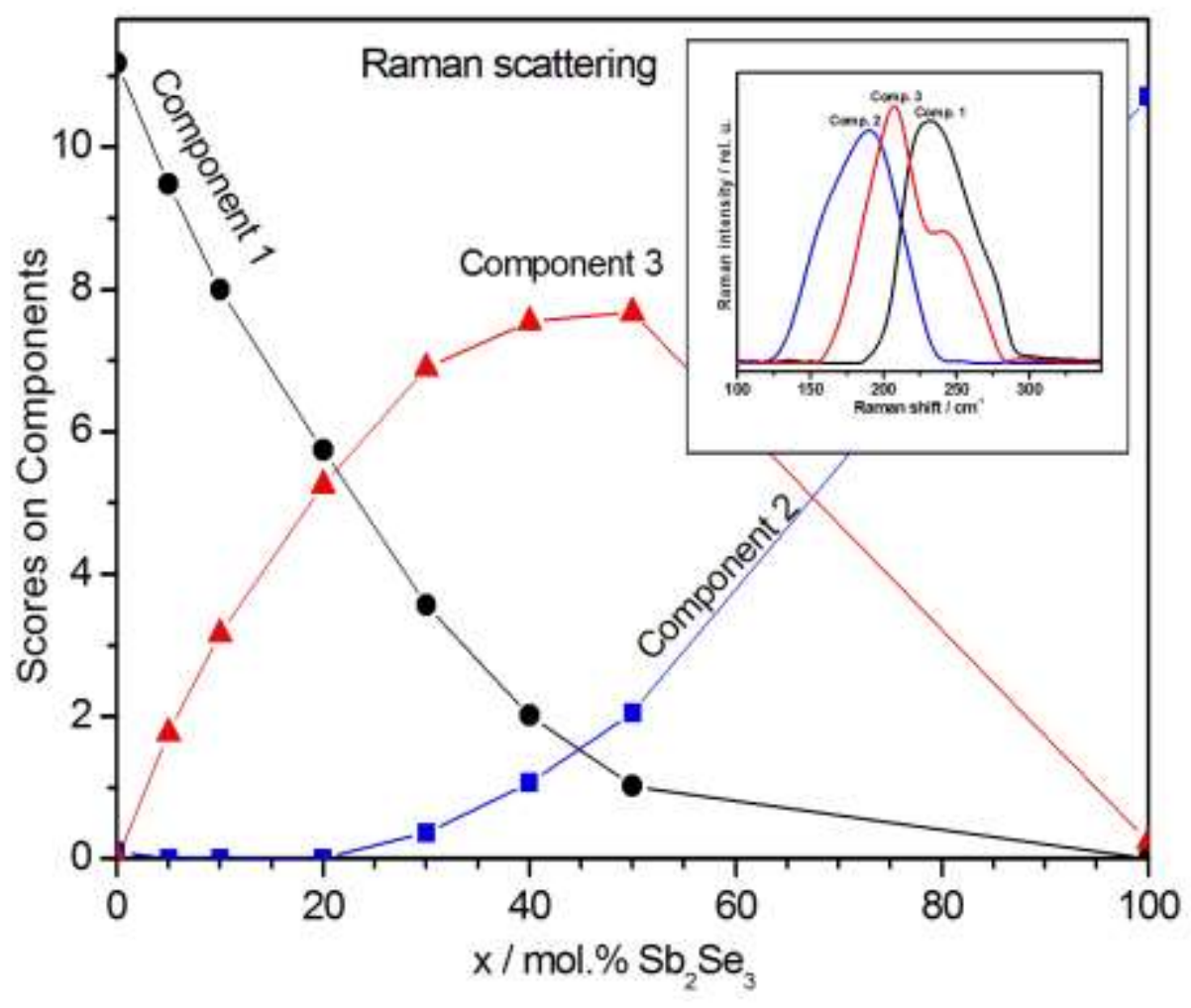

Fig. 5 


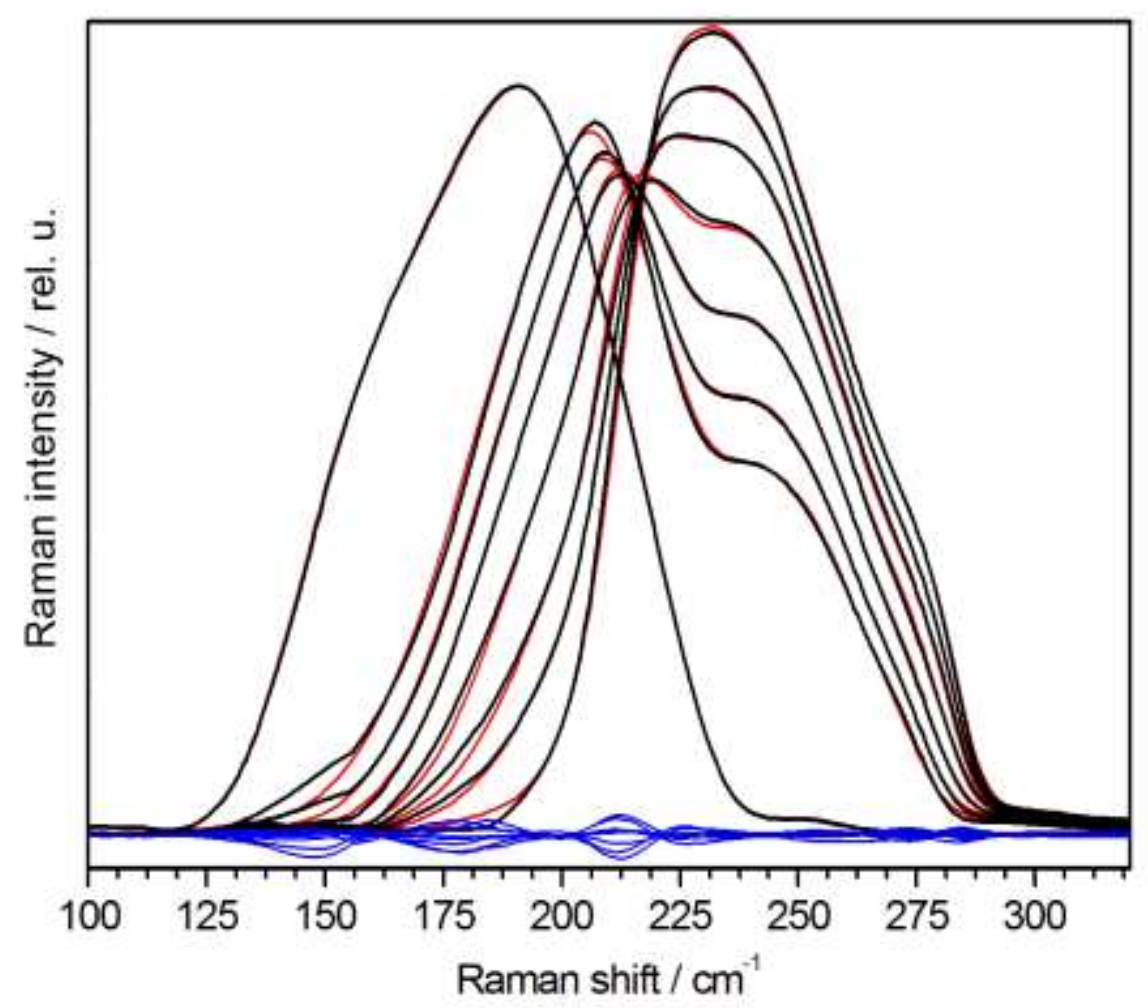

Fig. 6 


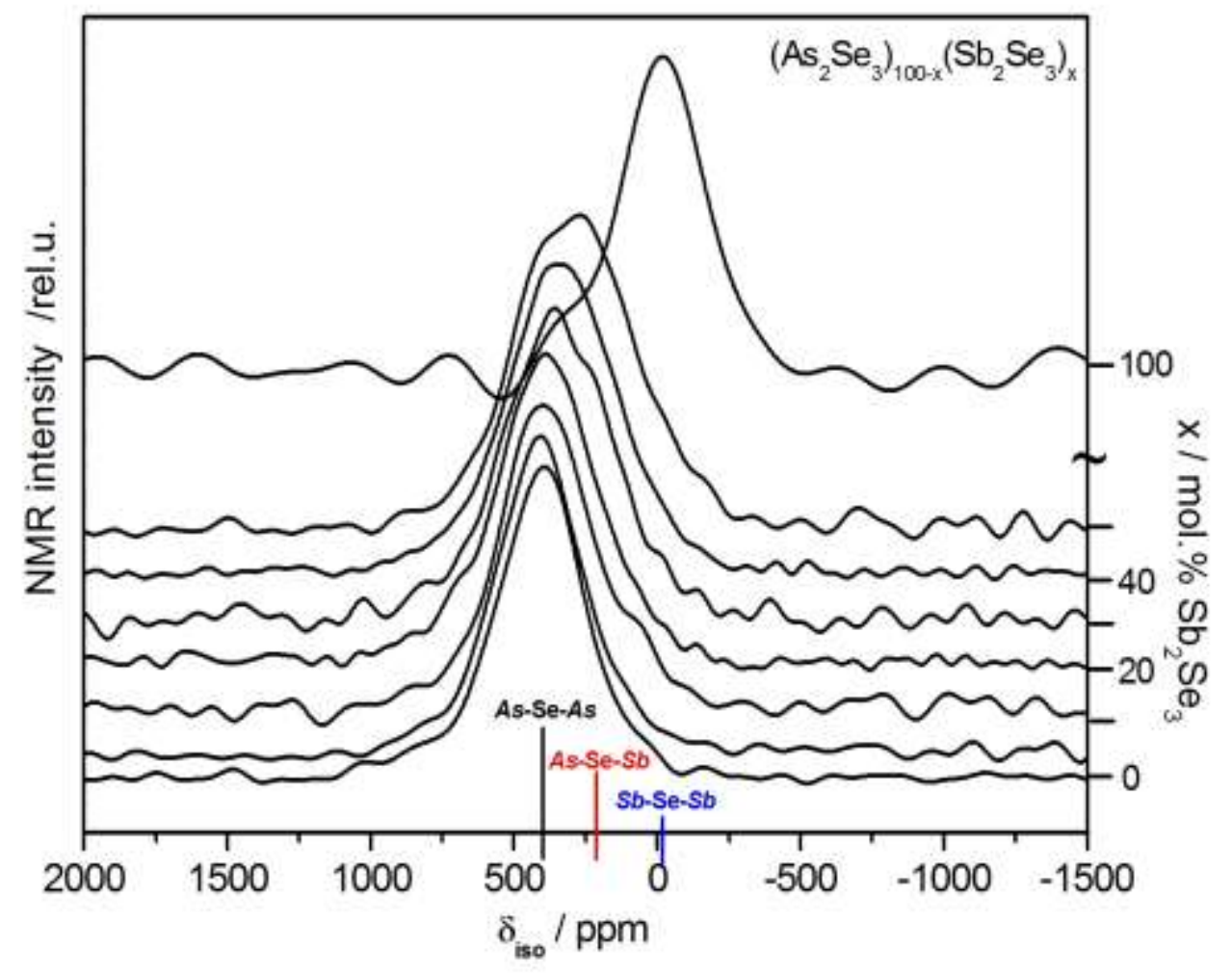

Fig. 7 


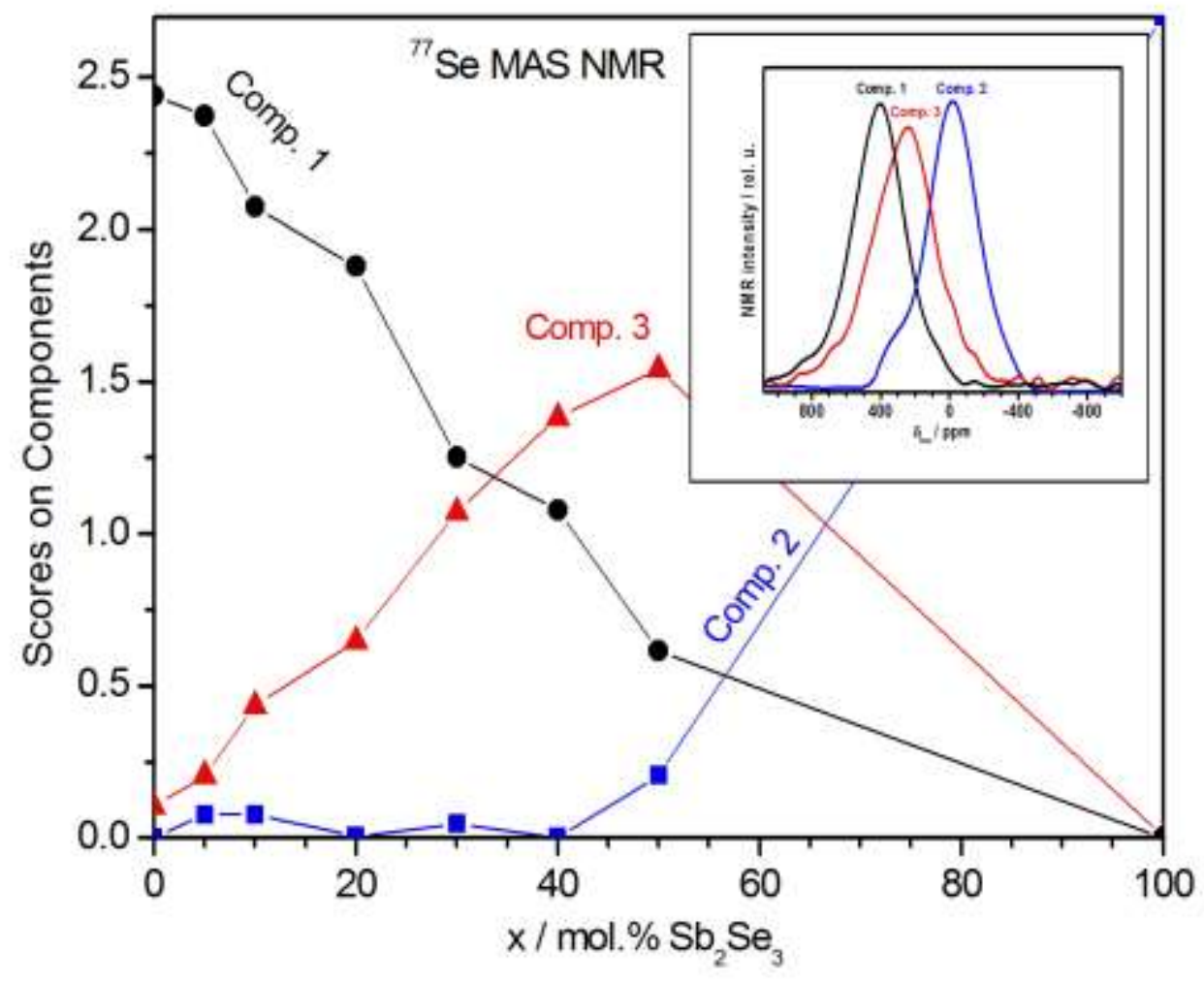

Fig. 8 


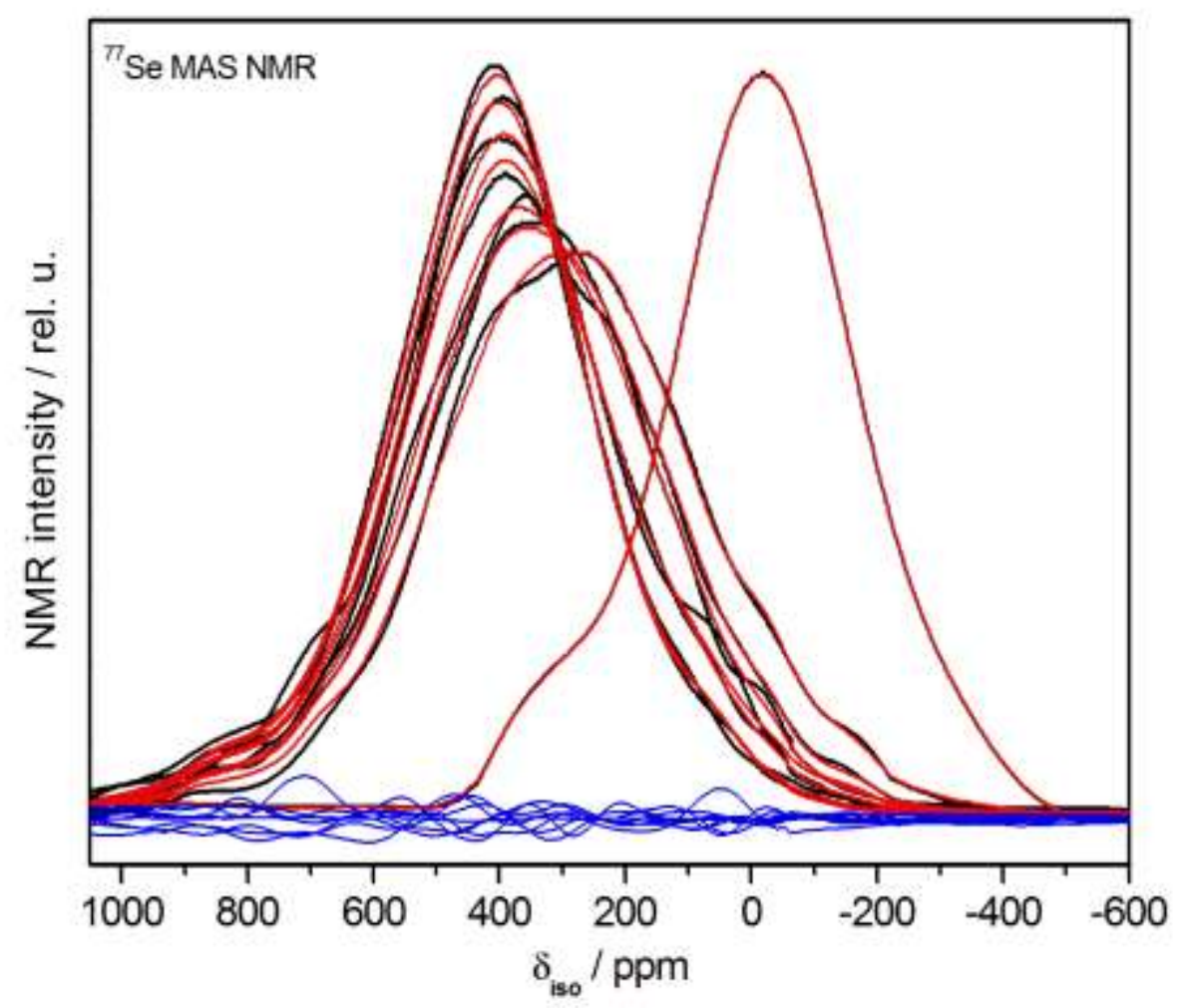

Fig. 9 


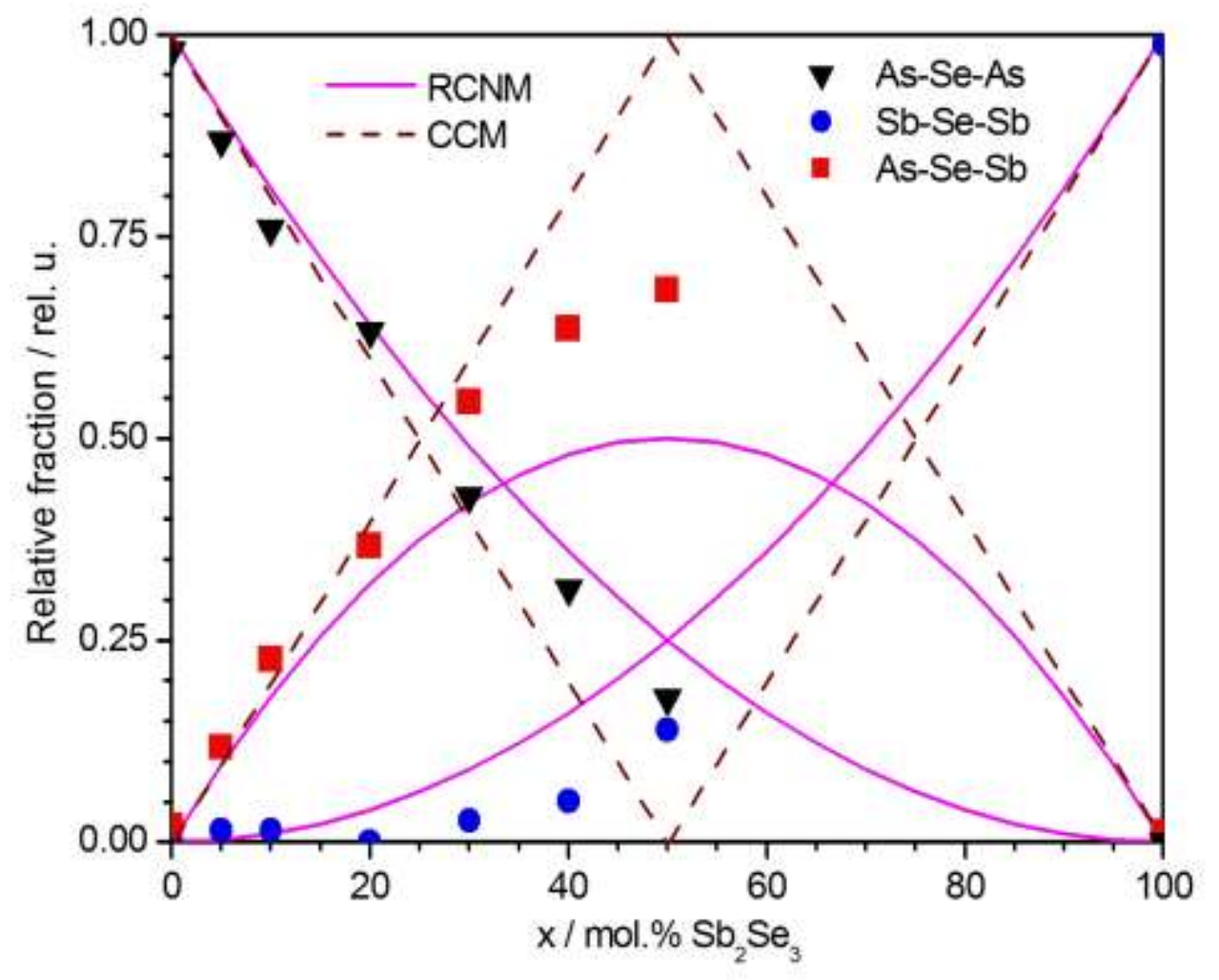

Fig. 10 